Article

\title{
Synthesis of Soluble Star-Shaped Polymers via In and Out Approach by Ring-Opening Metathesis Polymerization (ROMP) of Norbornene: Factors Affecting the Synthesis
}

\author{
Zelin Sun, Kazuya Morishita and Kotohiro Nomura *(1) \\ Department of Chemistry, Graduate School of Science, Tokyo Metropolitan University, 1-1 Minami Osawa, \\ Hachioji, Tokyo 192-0397, Japan; sz1689@163.com (Z.S.); kazukyun0607@yahoo.co.jp (K.M.) \\ * Correspondence: ktnomura@tmu.ac.jp; Tel.: +81-42-677-2547
}

Received: 10 November 2018; Accepted: 15 December 2018; Published: 19 December 2018

\begin{abstract}
The methods for one-pot synthesis of 'soluble' star-shaped polymers by sequential living ring-opening metathesis polymerization (ROMP) of norbornene (NBE) and cross-linking (CL) reagent using $\mathrm{Mo}\left(\mathrm{CHCMe}{ }_{2} \mathrm{Ph}\right)\left(\mathrm{N}-2,6{ }^{-}{ }^{i} \mathrm{Pr}_{2} \mathrm{C}_{6} \mathrm{H}_{3}\right)\left(\mathrm{O}^{t} \mathrm{Bu}\right)_{2}$ have been explored. The method (called the "in and out" or core-first approach) basically consists of (i) the living ROMP of NBE (formation of arm), (ii) reaction with CL (formation of core), (iii) additional living ROMP of NBE (propagating arms from the core, formation of star), (iv) end-modification via Wittig-type cleavage of metal-carbon double bonds containing polymer chain with aldehyde. Two different approaches in the core formation step (reaction with CL mixed with/without NBE) for synthesis of the high molecular weight star-shaped ROMP polymers with more branching, unimodal molecular weight distributions have been explored in detail. The method (reacting CL with NBE in the core formation step) under highly diluted conditions afforded the high molecular weight polymers with unimodal molecular weight distributions.
\end{abstract}

Keywords: metathesis; living polymerization; molybdenum; star-shaped polymers; ring-opening metathesis polymerization

\section{Introduction}

Star-shaped polymers consisting of linear arms connected at a central branched core are one of the simplest nonlinear polymers, and study for the precise synthesis by living polymerization technique attracts considerable attention [1-7]. Synthesis by adopting ring-opening metathesis polymerization (ROMP) [8-16] has been employed by sequential addition of monomers/cross linkers (CLs) [12,17-30], and the resultant polymers (soluble in organic solvent, such as toluene, chloroform, dichloromethane, etc.) were applied as fluorescent materials [19], supported catalysts [20], and as controlled release and drug delivery systems [24,26,27]. In this method, related examples for synthesis of cross-linked ROMP polymers (insoluble in common organic solvents) were also known [31-35], especially in terms of application as monolith materials. Two major approaches shown in Scheme 1, such as the "in and out" (core first) approach using a molybdenum-alkylidene catalyst [17-21], and arm (brush) first approach using a ruthenium-carbene catalyst [23-28], have been known for synthesis of 'soluble' star-shaped ROMP polymers. As observed in the synthesis by adopting other methods, such as controlled radical polymerization (atom transfer radical polymerization (ATRP), reversible addition-fragmentation chain-transfer polymerization (RAFT) techniques), the arm first approaches using a (commercially available) ruthenium-carbene catalyst generally require chromatographic purifications (including macromonomer (arm) purifications, 
as viscous oil) [29]. By contrast, the one-pot approach using a molybdenum catalyst (in and out approach) [17-21], $\mathrm{Mo}\left(\mathrm{CHCMe}_{2} \mathrm{Ph}\right)\left(\mathrm{N}-2,6-{ }^{i} \mathrm{Pr}_{2} \mathrm{C}_{6} \mathrm{H}_{3}\right)\left(\mathrm{O}^{t} \mathrm{Bu}\right)_{2}$ (Mo cat.), does not require tedious purification steps, and enables an introduction of a functionality to the polymer chain ends (star surface) via a Wittig-type reaction of metal-carbon double bond containing a polymer chain with certain aldehyde [12,16-21,36-38].
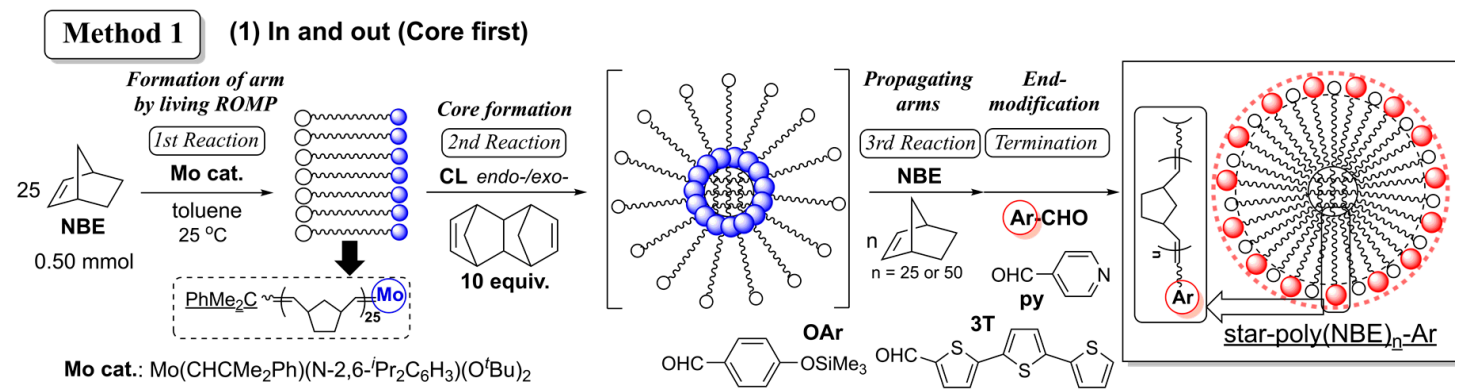

(2) Arm first (Bottle brush and CL)
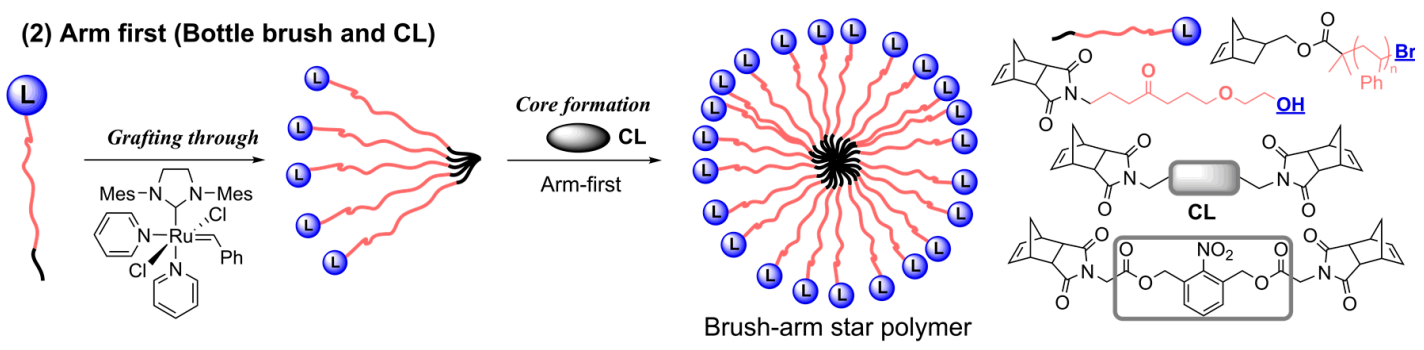

Scheme 1. Two approaches employed for synthesis of star-shaped polymers by living ring-opening metathesis polymerization (ROMP) of cyclic olefins by molybdenum, ruthenium catalysts. $\mathrm{NBE}=$ Norbornene, $\mathrm{CL}=$ Cross-linking.

For example, as shown in Scheme 2, pyridine modified 'soluble' star-shaped polymers, star-poly(NBE) $\mathbf{n}-\mathbf{P y}(\mathrm{n}=25,50)$, were used as the effective ligand for ruthenium catalyzed chemoselective hydrogen transfer reduction of various ketones, such as 5-hexen-2-one, 2-allyl-cyclohexanone, 5-isopropenyl-2-methylcyclohexanone (dihydrocarvone), and the activity by $\mathrm{RuCl}_{2}\left(\mathrm{PPh}_{3}\right)_{4}$ increased with addition of the star polymer ligand [20]. The catalyst could be recovered quantitatively by pouring the reaction mixture into methanol and could be reused without further purification; both the activity and the selectivity did not decrease in the several recycle runs [20]. Moreover, the observed catalytic activities were close to those using the supported catalysts with linear poly(NBE) containing pyridine at the chain end, suggesting that unique characteristics observed in the linear ROMP polymers could be preserved by placing the pyridine moiety on the star surface (and the star polymer supported catalysts showed better efficiency in the catalyst recycle) [20].

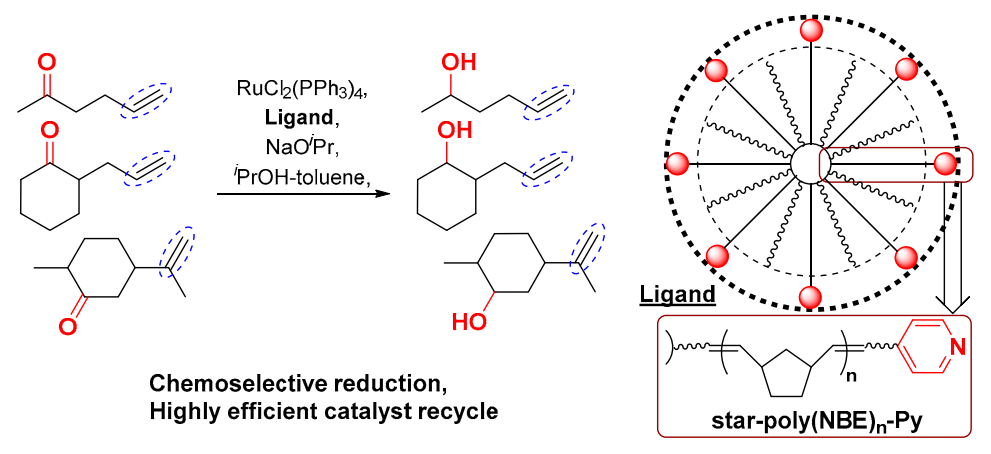

Scheme 2. Chemoselective hydrogen transfer reactions of ketones by efficient recyclable ruthenium catalyst supported by star-polymer ligand [20]. 
Since it was demonstrated that, as also described above, these ring-opened polymers, poly(NBE), possessed a rather linear nature compared to ordinary polymers prepared by vinyl additions exemplified by poly(acrylamide) due to the cyclic structure in the main chain [39], it is thus highly expected that these "surface-modified" star polymers can be used as advanced materials that cannot be achieved by ordinary end-modified linear and bottle brush polymers. However, previous reports [17-20], by adopting so-called Method 1 (shown in Scheme 1), only demonstrated synthesis of the 'soluble' polymers with a limited number of arms under limited conditions ( 5 or 10 equivalent of CL [17], shown below in Table 1) due to a difficulty of the molecular weight control, as also described below. Therefore, the development of a controlled synthesis of 'soluble' star-shaped ROMP polymers having more arms has been an important subject in terms of application of these star-shaped polymers as functional materials.

Table 1. Synthesis of star-shaped polymers by living ring-opening metathesis polymerization (ROMP) using $\mathrm{Mo}\left(\mathrm{CHCMe}{ }_{2} \mathrm{Ph}\right)\left(\mathrm{N}-2,6-{ }^{i} \mathrm{Pr}_{2} \mathrm{C}_{6} \mathrm{H}_{3}\right)\left(\mathrm{O}^{t} \mathrm{Bu}\right)_{2}(\text { Method } 2)^{a}$.

\begin{tabular}{|c|c|c|c|c|c|c|c|c|c|}
\hline \multirow[t]{2}{*}{ Run } & \multirow{2}{*}{$\begin{array}{c}\text { Toluene }^{b} / \mathrm{g} \\
\mathrm{x} / \mathrm{y} / \mathrm{z}\end{array}$} & \multicolumn{4}{|c|}{ 2nd } & \multirow{2}{*}{$\begin{array}{l}\text { 3rd } \\
\mathrm{NBE}^{c} \\
\text { /equiv }\end{array}$} & \multirow{2}{*}{$\frac{M_{\mathbf{n}}{ }^{e}}{/ \times 10^{-5}}$} & \multirow[t]{2}{*}{$M_{\mathrm{w}} / M_{\mathrm{n}}^{e}$} & \multirow{2}{*}{$\begin{array}{c}\text { Yield }^{f} \\
/ \%\end{array}$} \\
\hline & & $\begin{array}{l}\mathrm{CL}^{c} \\
\text { /equiv }\end{array}$ & $\begin{array}{l}\mathrm{NBE}^{c} \\
\text { /equiv }\end{array}$ & $\begin{array}{c}\text { conc. }^{d} \\
/ \times 10^{-2} \mathrm{M}\end{array}$ & $\begin{array}{l}\text { time } \\
/ \mathrm{min}\end{array}$ & & & & \\
\hline $1^{g}$ & $3.0 / 4.0 / 4.0$ & 10 & - & 8.67 & 50 & 25 & 0.88 & 1.19 & 96 \\
\hline $2^{g}$ & $3.0 / 4.0 / 4.0$ & 15 & - & 9.91 & 50 & 25 & 1.34 & 1.30 & 96 \\
\hline $3^{g}$ & $3.0 / 4.0 / 4.0$ & 15 & - & 9.91 & 70 & 25 & 2.08 & $2.88^{h}$ & 94 \\
\hline 4 & $3.0 / 4.0 / 4.0$ & 15 & 5 & 11.1 & 50 & 25 & 1.75 & $1.97^{h}$ & 95 \\
\hline 5 & $3.0 / 4.0 / 4.0$ & 15 & 5 & 11.1 & 70 & 25 & 2.13 & $2.22^{h}$ & 90 \\
\hline 6 & $3.0 / 4.0 / 4.0$ & 15 & 5 & 11.1 & 90 & 25 & 3.10 & $6.96^{h}$ & 99 \\
\hline 7 & $3.0 / 4.0 / 4.0$ & 15 & 5 & 11.1 & 120 & 25 & 3.45 & $4.74^{h}$ & 94 \\
\hline 8 & $3.0 / 4.0 / 4.0$ & 15 & 5 & 11.1 & 120 & 25 & 3.66 & $5.56^{h}$ & 90 \\
\hline $9^{g}$ & $5.0 / 4.0 / 6.0$ & 15 & - & 7.71 & 50 & 25 & 1.37 & 1.44 & 97 \\
\hline $10^{g}$ & $5.0 / 4.0 / 6.0$ & 15 & - & 7.71 & 70 & 25 & 1.44 & 1.46 & 99 \\
\hline 11 & $5.0 / 4.0 / 6.0$ & 15 & 5 & 8.67 & 50 & 25 & 1.45 & $1.73^{h}$ & 93 \\
\hline 12 & $5.0 / 4.0 / 6.0$ & 15 & 5 & 8.67 & 70 & 25 & 1.57 & $1.57^{h}$ & 95 \\
\hline 13 & $5.0 / 4.0 / 6.0$ & 15 & 5 & 8.67 & 90 & 25 & 1.93 & $2.05^{h}$ & 93 \\
\hline 14 & $5.0 / 4.0 / 6.0$ & 15 & 5 & 8.67 & 120 & 25 & 2.40 & $2.22^{h}$ & 93 \\
\hline $15^{g}$ & $11.0 / 4.0 / 5.0$ & 15 & - & 4.62 & 50 & 25 & 1.37 & 1.22 & 90 \\
\hline $16^{g}$ & $11.0 / 4.0 / 5.0$ & 15 & 5 & 5.20 & 50 & 25 & 1.45 & 1.28 & 91 \\
\hline $17^{g}$ & $11.0 / 4.0 / 5.0$ & 15 & - & 4.62 & 50 & 50 & 1.56 & $1.17^{h}$ & 96 \\
\hline $18^{g}$ & $11.0 / 4.0 / 5.0$ & 15 & 5 & 5.20 & 50 & 50 & 1.91 & $1.36^{h}$ & 98 \\
\hline $19^{g}$ & $11.0 / 4.0 / 5.0$ & 15 & - & 4.62 & 70 & 25 & 1.49 & 1.37 & 94 \\
\hline $20^{g}$ & $11.0 / 4.0 / 5.0$ & 15 & 5 & 5.20 & 70 & 25 & 1.53 & 1.39 & 96 \\
\hline $21^{g}$ & $11.0 / 4.0 / 5.0$ & 15 & - & 4.62 & 70 & 50 & 1.64 & $1.28^{h}$ & 94 \\
\hline $22^{g}$ & $11.0 / 4.0 / 5.0$ & 15 & 5 & 5.20 & 70 & 50 & 2.02 & $1.45^{h}$ & 99 \\
\hline
\end{tabular}

${ }^{a}$ Conditions: Toluene at $25{ }^{\circ} \mathrm{C}$ (detailed procedure, see Scheme 3, Method 2), 4-pyridine carboxaldehyde was used for termination. ${ }^{b}$ Amount of toluene (in gram) in each step (shown in Scheme 3). ${ }^{c}$ Equivalent to Mo. ${ }^{d}$ Calculated concentration of NBE $+\mathrm{CL}$ charged $(\mathrm{mmol} / \mathrm{L})$ at the second stage (core formation). ${ }^{e}$ Gel-permeation chromatography (GPC) data in tetrahydrofuran (THF) vs. polystyrene standards (g/mol). ${ }^{f}$ Isolated yield (\%) as $\mathrm{MeOH}$ insoluble fraction. ${ }^{g}$ Cited from Reference [21]. ${ }^{h}$ Bimodal (or multimodal) molecular weight distributions observed on GPC trace.

Recently, we reported an improved protocol for controlled synthesis of 'soluble' star-shaped polymers with more arms (branching) by the living ROMP technique using the Mo-alkylidene initiator by sequential additions of norbornene (NBE) and the cross-linker (CL), expressed as Method 1 in Schemes 1 and 3 (shown below), upon addition of CL (15 and 20 equivalent to Mo) [21]. It turned out that the polydispersity index (PDI, $M_{\mathrm{W}} / M_{\mathrm{n}}$ ) values became low with decreasing the monomer concentration (under diluted conditions) in the core formation step (reaction with $C L$ ), shown in Scheme 1 (introduced as Method 1) [21]. It also turned out that the $M_{n}$ values in the resultant polymers increased upon increasing the amount of NBE in the third step (3rd reaction in Method 1) consisting of unimodal molecular weight distributions $\left(M_{\mathrm{w}} / M_{\mathrm{n}}=1.17,1.28\right.$, shown below in Table 1$)$.

In this paper, we have explored two modified approaches (Methods 2 and 3, shown in Scheme 3) in the core formation step (varying cross-linking density, core size) for preparation of the polymers 
with different core sizes upon increasing the amount of CL and/or by mixing CL and NBE. We thus herein introduce factors affecting the precise synthesis of star-shaped ROMP polymers with (relatively) unimodal molecular weight distributions, by adopting the living ROMP technique. Since most methods (controlled radical, ROMP, etc.) face a difficulty of preparation of the polymers with "unimodal" molecular weight distributions and require separation for the obtainment of the desired star-shaped polymers with relatively controlled molecular weights [12,29], the report should be helpful for precise synthesis under optimized conditions.

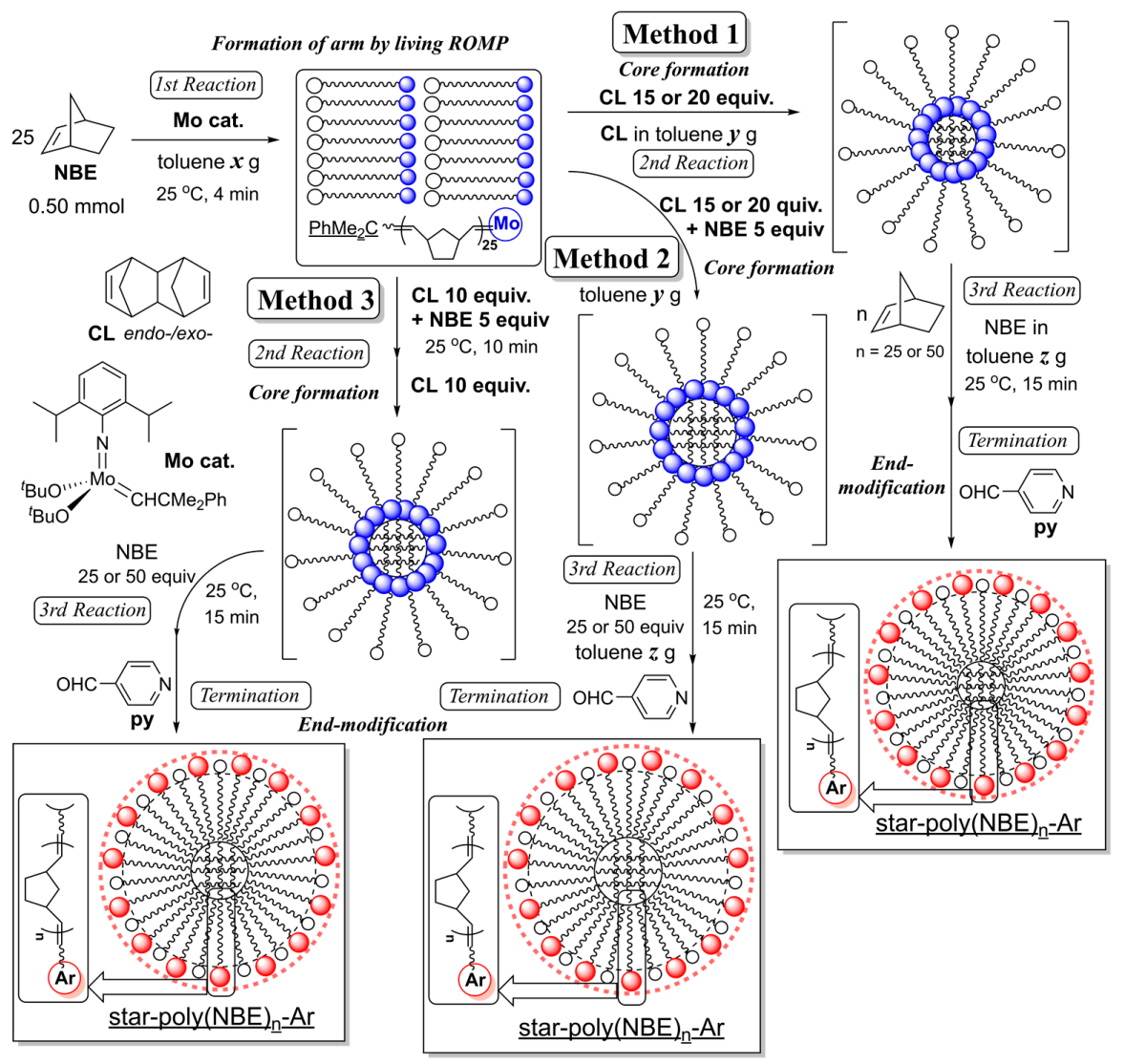

Scheme 3. Approaches explored for one-pot synthesis end-functionalized star-shaped ROMP polymers using molybdenum-alkylidene catalyst (Mo cat.).

\section{Results and Discussion}

\section{Synthesis of Pyridine Modified Star-Shaped Ring-Opened Poly(norbornene)}

As described in the introductory section, the method for synthesis of the titled star-shaped polymers using a molybdenum-alkylidene catalyst (Mo cat.), the so-called in and out (core first) approach, consists of (i) the living ROMP of norbornene (NBE, formation of arm), (ii) reaction with CL (formation of core), (iii) additional living ROMP of NBE (propagating arms from the core, formation of star), and (iv) end-modification via Wittig-type cleavage of metal-carbon double bonds containing polymer chain with aldehyde. In this method, an exclusive introduction of functionality into the ROMP polymer chain end can be easily achieved through a cleavage of the ROMP polymer-metal double bonds (of Schrock type Mo-alkylidene) with aldehyde, yielding a carbon-carbon double bond via a Wittig-like reaction [8-10,12,16]. Three modified approaches shown in Scheme 3 have thus been considered, because the approaches would prepare the polymers with different core sizes upon increasing the amount of CL (Method 1, Scheme 1) [21] and/or by mixing CL and NBE in the core formation step (varying cross-linking density, core size), as widely employed by the ATRP technique [5]. 
It has been known in the synthesis of star-shaped polymers using vinyl monomer and divinyl monomer (CL) by controlled radical polymerization that the degree of cross-linking or density of cross-linking (network structure, core size and density) can be tuned in the core formation step by combination of propagation and cross-linking (timing of adding CL during propagation) [5]. In this sense, the core size in the star-shaped ROMP polymers would be controlled (modified) by adopting combined ROMP of CL and NBE in the core formation step (2nd reaction, Methods 2 and 3, Scheme 3). Table 1 summarizes the results with the addition of NBE (5.0 equivalent) in the core formation step (Method 2, CL/Mo = 15, Scheme 3).

It turned out that, as observed previously (runs 2, 3) [21], the $M_{n}$ values in the resultant polymers increased over the reaction time $(50-120 \mathrm{~min}$, runs $4-8,11-14, \mathrm{CL} / \mathrm{Mo}=15)$, and the PDI values became large when the ROMPs were conducted under rather high CL/NBE concentration conditions $\left(M_{\mathrm{w}} / M_{\mathrm{n}}=1.97-6.96\right.$ (runs 4-7) vs. 1.57-2.22 (runs 11-14)). Under high dilution conditions (as conducted by Method 1, runs 15, 19), the resultant polymers became unimodal molecular weight distributions $\left(M_{\mathrm{w}} / M_{\mathrm{n}}=1.28,1.39\right.$, runs 16,20 , gel-permeation chromatography (GPC) traces are shown in Figure $1 \mathrm{c}, \mathrm{f}$ ), and the $M_{\mathrm{n}}$ values increased with the increase of NBE in the 3rd reaction (from 25 equivalent to 50 equivalent) with rather low PDIs (runs 18, 22) [21]. The observed increases in the $M_{n}$ values (e.g., $M_{n}=145,000$ (run 16) or 153,000 (run 20) vs. 191,000 (run 18) or 202,000 (run 22)) were apparently larger than that with the increase of the linear poly(NBE) $\left(2354\right.$, from 25 mer $\left(M_{n}=2354\right)$ to 50 mer $\left.\left(M_{n}=4708\right)\right)$, clearly indicating that the resultant polymers are star-shaped ROMP polymers consisting of core and poly(NBE) arms. It also turned out that the $M_{n}$ values in the resultant polymers were higher than those prepared by Method 1 in most cases. Moreover, the observed increases in the $M_{\mathrm{n}}$ value by Method 2 (e.g., 46,000 from 145,000 (runs 16, 25 equivalent NBE in the third step) to 191,000 (runs 18, 50 equivalent of NBE in the third step); 49,000 from 153,000 (runs 20, 25 equivalent of NBE in the third step) to 202,000 (runs 22, 50 equivalent of NBE in the third step)) are apparently larger than those by Method 1 (e.g., 19,000 from 137,000 (runs 15, 25 equivalent of NBE in the third step) to 156,000 (runs 17, 50 equivalent of NBE in the third step); 15,000 from 149,000 (runs 19, 25 equivalent of NBE in the third step) to 164,000 (runs 21, 50 equivalent of NBE in the third step)). It is thus strongly suggested that the resultant star-shaped ROMP polymers possess more branching (arms) than those prepared by Method 1. The resultant polymers prepared by Method 2 are soluble in toluene, tetrahydrofuran (THF), chloroform, and dichloromethane at room temperature.

Figure 1 shows selected GPC traces in the resultant polymers under different monomer concentrations in the 2 nd reaction (in Scheme 3, Method 2, CL/Mo $=15$ ). The resultant polymers prepared under rather high concentration conditions (Figure 1a,d; runs 4,5) showed bimodal molecular weight distributions (consisting of high and low molecular weights), and the extent in the high molecular weight trace decreased when the ROMPs were conducted under diluted conditions (Figure 1b,e; runs 11, 12). By contrast, the GPC traces became unimodal distributions when the ROMPs were conducted under high diluted conditions (Figure 1c,f; runs 16,18). It seems that the extent of a higher molecular GPC trace was decreased upon increasing the amount of toluene (or decreasing the monomer concentration); we speculate that this would probably be in order to avoid so-called star-star coupling (further intermolecular metathesis of the core molecules). Therefore, as observed in Method 1, control of monomer concentration in the 2nd step (core formation step) plays an important role for the obtainment of star-shaped ROMP polymers with unimodal molecular weight distributions.

Table 2 summarizes the results for the preparation of the star ROMP polymers by Method 2 under a high $\mathrm{CL} / \mathrm{Mo}$ ratio $(\mathrm{CL} / \mathrm{Mo}=20)$. The results also showed that the $M_{\mathrm{n}}$ values in the resultant ROMP polymers increased over the reaction time in the core formation (2nd step, runs 26-31, 34-37), and the PDI values became low when the ROMPs were conducted under diluted conditions $\left(M_{\mathrm{w}} / M_{\mathrm{n}}=1.58-2.22\right.$, runs 34-37). However, the resultant polymers still possessed bimodal molecular weight distributions (runs 34-37). It should be noted that the PDI values became low when the ROMPs (especially in the first and the second steps) were conducted under high diluted conditions. Moreover, as demonstrated in runs 38 and 40, a certain optimization of reaction time in the second step 
(50 $\mathrm{min}$ ) also seems important for the obtainment of the star-shaped ROMP polymers with unimodal molecular weight distributions $\left(M_{\mathrm{w}} / M_{\mathrm{n}}=1.52\right.$ (run 38), 1.43 (run 40)). It thus becomes clear that precise optimization of the conditions (dilution at the 2 nd reaction) should be necessary for obtainment the polymers with rather low PDI values.
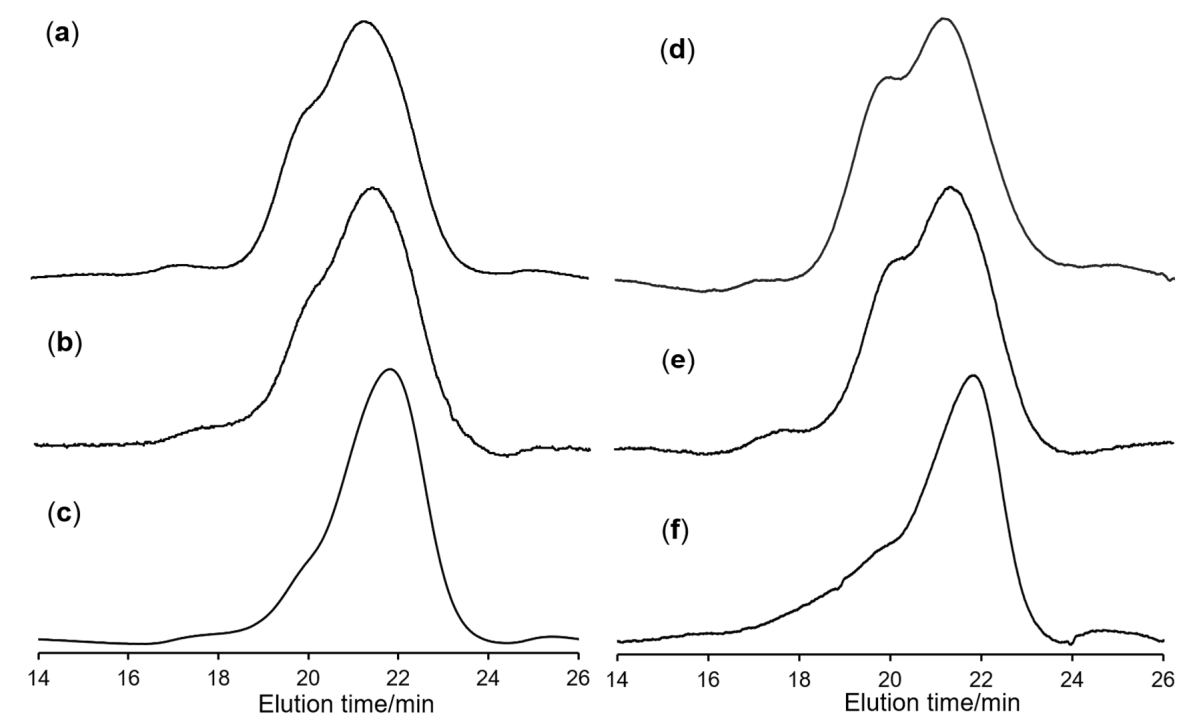

Figure 1. Selected GPC traces in the resultant polymers prepared by Method 2 (shown in Scheme 3, $\mathrm{CL} / \mathrm{Mo}=15)$. Reaction time at the second stage (core formation) $=50 \mathrm{~min}(\mathbf{a}-\mathbf{c}), 70 \mathrm{~min}(\mathbf{d}-\mathbf{f})$. Calculated concentration for NBE $+\mathrm{CL}=11.1 \times 10^{-2} \mathrm{M}\left((\mathbf{a})\right.$ run 4 , (d) run 5), $8.67 \times 10^{-2} \mathrm{M}(\mathbf{b})$ run 11, (e) run 12), and $5.20 \times 10^{-2} \mathrm{M}\left((\mathbf{c})\right.$ run $16, M_{\mathrm{n}}=1.45 \times 10^{5}, M_{\mathrm{w}} / M_{\mathrm{n}}=1.28 ;(\mathbf{f})$ run $20, M_{\mathrm{n}}=1.53 \times 10^{5}$, $\left.M_{\mathrm{W}} / M_{\mathrm{n}}=1.39\right)$. Detailed data are shown in Table 1 .

Table 2. Synthesis of star-shaped polymers by living ring-opening metathesis polymerization (ROMP) using $\mathrm{Mo}\left(\mathrm{CHCMe}_{2} \mathrm{Ph}\right)\left(\mathrm{N}-2,6-{ }^{i} \mathrm{Pr}_{2} \mathrm{C}_{6} \mathrm{H}_{3}\right)\left(\mathrm{O}^{t} \mathrm{Bu}\right)_{2}\left(\right.$ Method 2) ${ }^{a}$.

\begin{tabular}{|c|c|c|c|c|c|c|c|c|c|}
\hline \multirow[t]{2}{*}{ Run } & \multirow{2}{*}{$\begin{array}{c}\text { Toluene }^{b} / \mathrm{g} \\
\mathrm{x} / \mathrm{y} / \mathrm{z}\end{array}$} & \multicolumn{4}{|c|}{ 2nd } & \multirow{2}{*}{$\begin{array}{l}\text { 3rd } \\
\mathrm{NBE}^{c} \\
\text { /equiv }\end{array}$} & \multirow{2}{*}{$\frac{M_{\mathrm{n}}{ }^{e}}{/ \times 10^{-5}}$} & \multirow[t]{2}{*}{$M_{\mathrm{w}} / M_{\mathrm{n}}^{e}$} & \multirow{2}{*}{$\frac{\text { Yield } f}{1 \%}$} \\
\hline & & $\begin{array}{l}C L^{c} \\
\text { /equiv }\end{array}$ & $\begin{array}{l}\mathrm{NBE}^{c} \\
\text { /equiv }\end{array}$ & $\begin{array}{c}\text { conc. }^{d} \\
/ \times 10^{-2} \mathrm{M}\end{array}$ & $\begin{array}{l}\text { time } \\
/ \mathrm{min}\end{array}$ & & & & \\
\hline $23 g$ & $3.0 / 4.0 / 4.0$ & 20 & - & 11.1 & 50 & 25 & 2.86 & $2.51^{h}$ & 95 \\
\hline $24^{g}$ & $3.0 / 4.0 / 4.0$ & 20 & - & 11.1 & 70 & 25 & 3.49 & $4.31^{h}$ & 98 \\
\hline $25^{g}$ & $3.0 / 4.0 / 4.0$ & 20 & - & 11.1 & 90 & 25 & 2.86 & $2.19^{h}$ & 90 \\
\hline 26 & $3.0 / 4.0 / 4.0$ & 20 & 5 & 12.4 & 50 & 25 & 2.98 & $5.91^{h}$ & 94 \\
\hline 27 & $3.0 / 4.0 / 4.0$ & 20 & 5 & 12.4 & 90 & 25 & 2.99 & $2.29^{h}$ & 98 \\
\hline 28 & $5.0 / 4.0 / 6.0$ & 20 & 5 & 9.63 & 50 & 25 & 2.36 & $2.26^{h}$ & 99 \\
\hline 29 & $5.0 / 4.0 / 6.0$ & 20 & 5 & 9.63 & 70 & 25 & 2.93 & $2.56^{h}$ & 94 \\
\hline 30 & $5.0 / 4.0 / 6.0$ & 20 & 5 & 9.63 & 90 & 25 & 2.64 & $2.34^{h}$ & 99 \\
\hline 31 & $5.0 / 4.0 / 6.0$ & 20 & 5 & 9.63 & 120 & 25 & 2.74 & $2.04^{h}$ & 99 \\
\hline $32^{g}$ & $11.0 / 4.0 / 5.0$ & 20 & - & 5.20 & 50 & 25 & 1.49 & $1.44^{h}$ & 90 \\
\hline $33^{g}$ & $11.0 / 4.0 / 5.0$ & 20 & - & 5.20 & 70 & 25 & 1.78 & $1.54^{h}$ & 91 \\
\hline 34 & $11.0 / 4.0 / 5.0$ & 20 & 5 & 5.78 & 50 & 25 & 1.40 & $1.58^{h}$ & 99 \\
\hline 35 & $11.0 / 4.0 / 5.0$ & 20 & 5 & 5.78 & 70 & 25 & 1.64 & $1.91^{h}$ & 98 \\
\hline 36 & $11.0 / 4.0 / 5.0$ & 20 & 5 & 5.78 & 90 & 25 & 1.81 & $2.20^{h}$ & 98 \\
\hline 37 & $11.0 / 4.0 / 5.0$ & 20 & 5 & 5.78 & 120 & 25 & 2.14 & $2.22^{h}$ & 94 \\
\hline 38 & $11.0 / 8.0 / 5.0$ & 20 & 5 & 4.56 & 50 & 25 & 1.53 & 1.52 & 99 \\
\hline 39 & $11.0 / 8.0 / 5.0$ & 20 & 5 & 4.56 & 70 & 25 & 1.68 & $1.51^{h}$ & 97 \\
\hline 40 & $15.0 / 8.0 / 5.0$ & 20 & 5 & 3.77 & 50 & 25 & 1.52 & 1.43 & 99 \\
\hline 41 & $15.0 / 8.0 / 5.0$ & 20 & 5 & 3.77 & 70 & 25 & 1.64 & $1.46^{h}$ & 98 \\
\hline
\end{tabular}

${ }^{a}$ Conditions: Toluene at $25{ }^{\circ} \mathrm{C}$ (detailed procedure, see Scheme 3, Method 2), 4-pyridine carboxaldehyde was used for termination. ${ }^{b}$ Amount of toluene (in gram) in each step (shown in Scheme 3). ${ }^{c}$ Equivalent to Mo. ${ }^{d}$ Calculated concentration of NBE + CL charged $(\mathrm{mmol} / \mathrm{L})$ at the second stage (core formation). ${ }^{e}$ GPC data in THF vs. polystyrene standards $(\mathrm{g} / \mathrm{mol}) .{ }^{f}$ Isolated yield $(\%)$ as $\mathrm{MeOH}$ insoluble fraction. ${ }^{g}$ Cited from Reference [21].

${ }^{h}$ Bimodal (or multimodal) molecular weight distributions observed on GPC trace. 
In order to obtain the higher molecular weight polymers (with more branching) with unimodal molecular weight distributions, two step reactions were attempted in the core formation step (Method 3, Scheme 3). In this method, 10 equivalent of CL and 5.0 equivalent of NBE were added into a solution of the initial ROMP with NBE (1st step), and the solution was stirred for $10 \mathrm{~min}$ (expecting formation of the initial core), and 10 equivalent of $C L$ was then further added into the solution and stirring of the mixture was continued for a certain period in the 2nd step. The results are summarized in Table 3.

Table 3. Synthesis of star-shaped polymers by living ring-opening metathesis polymerization (ROMP) using $\mathrm{Mo}\left(\mathrm{CHCMe}{ }_{2} \mathrm{Ph}\right)\left(\mathrm{N}-2,6-{ }^{i} \mathrm{Pr}_{2} \mathrm{C}_{6} \mathrm{H}_{3}\right)\left(\mathrm{O}^{t} \mathrm{Bu}\right)_{2}\left(\right.$ Method 3) ${ }^{a}$.

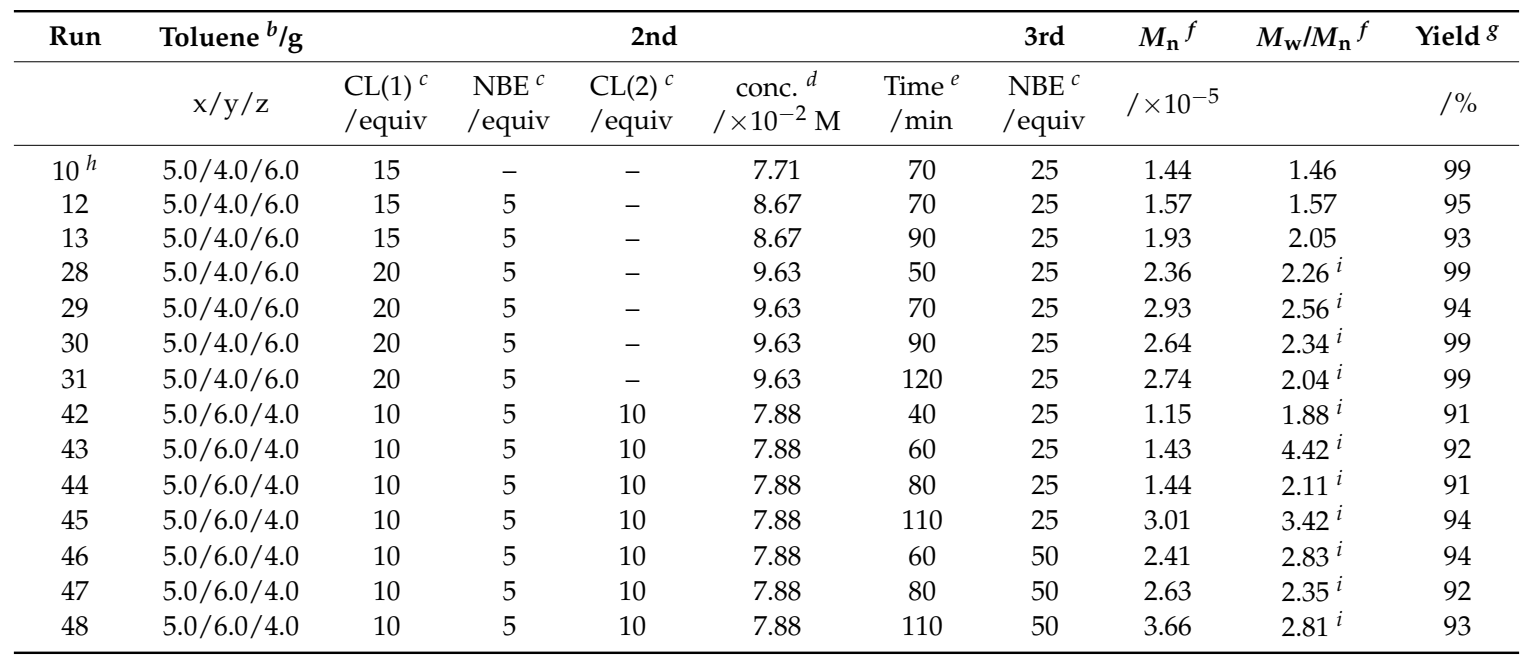

${ }^{a}$ Conditions: Toluene at $25^{\circ} \mathrm{C}$ (detailed procedure, see Scheme 3, Method 3), 4-pyridine carboxaldehyde was used for termination. ${ }^{b}$ Amount of toluene (in gram) in each step (shown in Scheme 3). ${ }^{c}$ Equivalent to Mo. ${ }^{d}$ Calculated concentration of NBE $+\mathrm{CL}$ charged (mmol/L) at the second stage (core formation). ${ }^{e}$ Reaction time after adding $\mathrm{CL}(2) .{ }^{f}$ GPC data in THF vs. polystyrene standards $(\mathrm{g} / \mathrm{mol}) .{ }^{g}$ Isolated yield (\%) as $\mathrm{MeOH}$ insoluble fraction.

${ }^{h}$ Cited from Reference [21]. ${ }^{i}$ Bimodal (or multimodal) molecular weight distributions observed on GPC trace.

It turned out that, as observed in Table 2 as well as in Method 1 [21], the $M_{\mathrm{n}}$ values in the resultant polymers increased over the reaction time in the 2nd step (40-110 $\mathrm{min}$, runs $42-45)$. However, the PDI values (in the polymers prepared by Method 3) were larger $\left(M_{\mathrm{w}} / M_{\mathrm{n}}=1.88-4.42\right)$ than those prepared by Method $2\left(M_{\mathrm{w}} / M_{\mathrm{n}}=2.04-2.56\right)$; the PDI values did not improve upon increasing the amount of NBE in the 3rd step (runs 46-48). We thus speculate that this would be due to enhanced star-star coupling (intermolecular metathesis with the initial cores), and the approach in Method 3 is not suitable for this purpose.

\section{Concluding Remarks}

In this paper, two methods, which are different in the core formation step (2nd reaction), shown in Scheme 3, have been explored for one-pot synthesis of star-shaped ROMP polymers with more branching (arms). Although these reactions required conditions with high dilution for the obtainment of polymers with unimodal molecular weight distributions, as reported previously [21], the number of the poly(NBE) arms can be increased upon increasing the CL (higher CL/Mo ratio, 15, 20, Method 1, Scheme 3). Moreover, the core size can also be controlled upon copresence of NBE (use of CL and NBE in the 2nd step, Method 2, Scheme 3). It is thus possible to prepare high molecular weight star-shaped ROMP polymers with unimodal molecular weight distributions by adopting these approaches, especially by Methods 1 and 2. An introduction of a functional group into the ROMP polymer chain ends (star polymer surface) can also be attained by adopting these methods using molybdenum catalyst [12,16-21], as described in the introduction. We thus believe that the method should be applied for controlled synthesis of functional materials as surface modified star-shaped polymers. 


\section{Experimental Section}

\subsection{General Procedure}

All experiments were carried out under a nitrogen atmosphere in a vacuum atmospheres dry-box or using standard Schlenk techniques. All chemicals used were of reagent grades and were purified by the standard purification procedures. Anhydrous grade toluene (Kanto Chemical Co., Inc., Tokyo, Japan) was transferred into a bottle containing molecular sieves (mixture of $3 \mathrm{~A} 1 / 16,4 \mathrm{~A} 1 / 8$, and 13X 1/16) in the dry-box, and was stored over sodium/potassium alloy, and was used after passing through an alumina short column under nitrogen flow prior to use. $\mathrm{Mo}(\mathrm{CHCMe} 2 \mathrm{Ph})\left(\mathrm{N}-2,6-{ }^{i} \mathrm{Pr}_{2} \mathrm{C}_{6} \mathrm{H}_{3}\right)\left(\mathrm{O}^{t} \mathrm{Bu}\right)_{2}[40]$ and 1,4,4a,5,8,8a-hexahydro-1,4,5,8-exo-endo-dimethanonaphtalene ( $\mathrm{CL}$, exo:endo $=0.15: 1.00)$ [41] were prepared according to the literature, while 4-Pyridinecarboxaldehyde was used in the dry-box as received (Aldrich Chemical Co., St. Louis, MO, USA) without further purification.

Molecular weights and the molecular weight distributions of the resultant polymers were measured by gel-permeation chromatography (GPC). HPLC-grade THF (Wako Pure Chemical Ind., Inc., Tokyo, Japan) was used for GPC and was degassed prior to use. GPC were performed at $40{ }^{\circ} \mathrm{C}$ on a Shimadzu SCL-10A using a RID-10A detector (Shimadzu Co. Ltd., Kyoto, Japan) in THF (containing $0.03 \mathrm{wt} \%$ 2,6-di-tert-butyl-p-cresol, flow rate $1.0 \mathrm{~mL} / \mathrm{min}$ ). GPC columns (ShimPAC GPC-806, 804 and $802,30 \mathrm{~cm} \times 8.0 \mathrm{~mm} \varphi$ ) were calibrated versus polystyrene standard samples. ${ }^{1} \mathrm{H}$ and ${ }^{13} \mathrm{C}$ NMR spectra were recorded on a Bruker AV500 spectrometer $\left({ }^{1} \mathrm{H}, 500.13 \mathrm{MHz} ;{ }^{13} \mathrm{C}, 125.77 \mathrm{MHz}\right)$, and all chemical shifts are quoted in ppm and are referenced to $\mathrm{SiMe}_{4}$. Obvious multiplicities and routine coupling constants are usually not listed, and all spectra were obtained in the solvent indicated at $25^{\circ} \mathrm{C}$.

\subsection{General Polymerization Procedure}

A typical polymerization procedure (run 35, Method 2, Table 2) is as follows. A toluene solution $(1.0 \mathrm{~g})$ containing $\mathrm{Mo}(\mathrm{CHCMe} 2 \mathrm{Ph})\left(\mathrm{N}-2,6-{ }^{i} \mathrm{Pr}_{2} \mathrm{C}_{6} \mathrm{H}_{3}\right)\left(\mathrm{O}^{t} \mathrm{Bu}\right)_{2}\left(2.00 \times 10^{-5} \mathrm{~mol}\right)$ was added in one portion to a rapidly stirred toluene solution $(10.0 \mathrm{~g})$ containing the norbornene (25 equiv. to $\mathrm{Mo}$ ) at room temperature $\left(25^{\circ} \mathrm{C}\right)$, and the solution was stirred for $4 \mathrm{~min}$. A toluene solution $(4.0 \mathrm{~g})$ containing 1,4,4a,5,8,8a-hexahydro-1,4,5,8-exo-endo-dimethanonaphtalene (CL, 20 equivalent to Mo) and norbornene (NBE, 5 equivalent to Mo) was then added into the solution, and the mixture was stirred for the prescribed time ( $50 \mathrm{~min})$. Then, a toluene solution $(5.0 \mathrm{~g})$ containing NBE (25 equivalent to $\mathrm{Mo}$ ) was added in one portion to the mixture, and the reaction solution was further stirred for $15 \mathrm{~min}$. The polymerization was quenched by adding 4-pyridine carboxaldehyde (ca. >10 mg, excess), and the solution was stirred for $1 \mathrm{~h}$ for completion. The mixture was then removed in vacuo until it was dissolved in the minimum amount of toluene. The solution was poured dropwise into methanol to afford pale white precipitates. The polymer was then collected by filtration and dried in vacuo. In Method 1, the basic procedure was the same except that a toluene solution containing only CL $(15.0 / 20.0$ equivalent to Mo) was added in the second step.

In Method 3, the basic procedure was the same except for the amount of toluene at each step; the polymerization procedure of Method 3 (run 45, Method 3, Table 3) is as follows. A toluene solution (1.0 g) containing $\mathrm{Mo}\left(\mathrm{CHCMe}{ }_{2} \mathrm{Ph}\right)\left(\mathrm{N}-2,6-{ }^{i} \mathrm{Pr}_{2} \mathrm{C}_{6} \mathrm{H}_{3}\right)\left(\mathrm{O}^{t} \mathrm{Bu}\right)_{2}\left(2.00 \times 10^{-5} \mathrm{~mol}\right)$ was added in one portion to a rapidly stirred toluene solution $(4.0 \mathrm{~g})$ containing the norbornene (25 equiv. to $\mathrm{Mo}$ ) at room temperature $\left(25^{\circ} \mathrm{C}\right)$, and the solution was stirred for $4 \mathrm{~min}$. A toluene solution ( $\left.3.0 \mathrm{~g}\right)$ containing 1,4,4a, $5,8,8 \mathrm{a}-$ hexahydro-1,4,5,8-exo-endo-dimethanonaphtalene (CL, 10 equivalent to $\mathrm{Mo}$ ) and norbornene (NBE, 5 equivalent to Mo) was then added into the solution, and the mixture was stirred for $10 \mathrm{~min}$; afterwards, a toluene solution ( $3.0 \mathrm{~g}$ ) containing 1,4,4a,5,8,8a-hexahydro-1,4,5,8-exo-endo-dimethanonaphtalene (CL, 10 equivalent to $\mathrm{Mo}$ ) was further added, and the mixture was stirred for the prescribed time (50 $\mathrm{min}$ ). Then, a toluene solution ( $4.0 \mathrm{~g}$ ) containing NBE (25 equivalent to Mo) was added in one portion to the mixture, and the reaction solution was further stirred for $15 \mathrm{~min}$. The polymerization was also quenched by adding 4-pyridine carboxaldehyde (ca. $>10 \mathrm{mg}$, excess), and the solution was stirred for $1 \mathrm{~h}$ for completion. 
Selected NMR spectra of star-shaped polymer were confirmed in the previously report [21]. ${ }^{1} \mathrm{H}$ NMR (in $\mathrm{CDCl}_{3}$ at $25^{\circ} \mathrm{C}$ ) (Table 1, run 9): $\delta 5.35$ and 5.21 (br.s, $2 \mathrm{H}$ olefinic), 2.79 and 2.43 (br.s, $2 \mathrm{H}$ ), 1.85 and $1.03(\mathrm{~m}, 2 \mathrm{H}), 1.78$, and $1.36(\mathrm{~m}, 4 \mathrm{H}) \mathrm{ppm}$. Moreover, resonance ascribed to the pyridine end group (8.54 and 8.50 (d) ppm) was also observed. ${ }^{13} \mathrm{C} \mathrm{NMR} \mathrm{(in} \mathrm{CDCl}_{3}$ at $25{ }^{\circ} \mathrm{C}$ ) (Table 1, run 4): $\delta$ 133.9, 133.0, $128.2,43.1,38.6,33.2,32.2 \mathrm{ppm}$.

Author Contributions: Conceptualization, K.N.; investigation, Z.S. and K.M.; s data analysis, Z.S. and K.N.; supervision, K.N.; writing —original draft preparation, Z.S. and K.N.; Project administration, K.N.

Funding: This project is partly supported by Grant-in-Aid for Challenging Exploratory Research (24656491, 15K14225), the Japan Society for the Promotion of Science (JSPS).

Acknowledgments: S.Z. acknowledges the Tokyo Metropolitan government (Tokyo Human Resources Fund for City Diplomacy) for pre-doctoral fellowship. The authors express their thanks to S. Komiya, K. Tsutsumi, and A. Inagaki (Tokyo Metropolitan Univ.) for helpful discussions.

Conflicts of Interest: The authors declare no conflict of interest.

\section{References}

1. Matyjaszewski, K. Macromolecular Engineering: From Precise Macromolecular Synthesis to Macroscopic Materials Properties and Applications; Matyjaszewski, K., Gnanou, Y., Leibler, L., Eds.; Wiley-VCH: Weinheim, Germany, 2007.

2. Hadjichristidis, N.; Pitsikalis, M.; Pispas, S.; Iatrou, H. Polymers with complex architecture by living anionic polymerization. Chem. Rev. 2001, 101, 3747-3792. [CrossRef] [PubMed]

3. Hirao, A.; Hayashi, M.; Loykulnant, S.; Sugiyama, K.; Ryu, S.W.; Haraguchi, N.; Matsuo, A.; Higashihara, T. Precise syntheses of chain-multi-functionalized polymers, star-branched polymers, star-linear block polymers, densely branched polymers, and dendritic branched polymers based on iterative approach using functionalized 1,1-diphenylethylene derivatives. Prog. Polym. Sci. 2005, 30, 111-182. [CrossRef]

4. Matyjaszewski, K.; Tsarevsky, N.V. Macromolecular engineering by atom transfer radical polymerization. J. Am. Chem. Soc. 2014, 136, 6513-6533. [CrossRef]

5. Matyjaszewski, K.; Tsarevsky, N.V. Nanostructured functional materials prepared by atom transfer radical polymerization. Nat. Chem. 2009, 1, 276-288. [CrossRef]

6. Khana, K.; Varshney, S.; Kakkar, A. Miktoarm star polymers: Advances in synthesis, self-assembly, and applications. Polym. Chem. 2010, 1, 1171-1185. [CrossRef]

7. Ren, J.M.; McKenzie, T.G.; Fu, Q.; Wong, E.H.H.; Xu, J.; An, Z.; Shanmugam, S.; Davis, T.P.; Boyer, C.; Qiao, G.G. Star polymers. Chem. Rev. 2016, 116, 6743-6836. [CrossRef]

8. Buchmeiser, M.R. Homogeneous metathesis polymerization by well-defined group VI and group VIII transition-metal alkylidenes: Fundamentals and applications in the preparation of advanced materials. Chem. Rev. 2000, 100, 1565-1604. [CrossRef] [PubMed]

9. Grubbs, R.H. (Ed.) Handbook of Metathesis; Wiley-VCH: Weinheim, Germany, 2003; Volume 3.

10. Buchmeiser, M. (Ed.) Metathesis Polymerisation; Springer: Berlin/Heidelberg, Germany, 2005.

11. Hilf, S.; Kilbinger, A.F.M. Functional end groups for polymers prepared using ring-opening metathesis polymerization. Nat. Chem. 2009, 1, 537-546. [CrossRef] [PubMed]

12. Nomura, K.; Abdellatif, M.M. Precise synthesis of polymers containing functional end groups by living ring-opening metathesis polymerization (ROMP): Efficient tools for synthesis of block/graft copolymers. Polymer 2010, 51, 1861-1881. [CrossRef]

13. Leitgeb, A.; Wappel, J.; Slugovc, C. The ROMP toolbox upgraded. Polymer 2010, 51, 2927-2946. [CrossRef]

14. Grubbs, R.H. Handbook of Metathesis, 2nd ed.; Grubbs, R.H., Khosravi, E., Eds.; Wiley-VCH: Weinheim, Germany, 2015; Volume 3.

15. Lunn, D.J.; Discekici, E.H.; de Alaniz, J.R.; Gutekunst, W.R.; Hawker, C.J. Established and emerging strategies for polymer chain-end modification. J. Polym. Sci. Part A Polym. Chem. 2017, 55, 2903-2914. [CrossRef]

16. Chen, Y.; Abdellatif, M.M.; Nomura, K. Olefin metathesis polymerization: Some recent developments in the precise polymerizations for synthesis of advanced materials (by ROMP, ADMET). Tetrahedron 2018, 74, 619-643. [CrossRef] 
17. Nomura, K.; Watanabe, Y.; Fujita, S.; Fujiki, M.; Otani, H. Facile controlled synthesis of soluble star shape polymers by ring-opening metathesis polymerization (ROMP). Macromolecules 2009, 42, 899-901. [CrossRef]

18. Otani, H.; Fujita, S.; Watanabe, Y.; Fujiki, M.; Nomura, K. A facile, controlled synthesis of soluble star polymers containing a sugar residue by ring-opening metathesis polymerization (ROMP). Macromol. Symp. 2010, 293, 53-57. [CrossRef]

19. Takamizu, K.; Nomura, K. Synthesis of oligo(thiophene) coated star shape ROMP polymers: Unique emission properties by the precise integration of functionality. J. Am. Chem. Soc. 2012, 134, 7892-7895. [CrossRef] [PubMed]

20. Nomura, K.; Tanaka, K.; Fujita, S. Use of pyridine coated star shape ROMP polymers as the supported ligand for Ru-catalyzed chemoselective hydrogen transfer reduction of ketones. Organometallics 2012, 31, 5074-5080. [CrossRef]

21. Sun, Z.; Nomura, K. One-pot synthesis of end-functionalised soluble star-shaped polymers by living ring-opening metathesis polymerisation using molybdenum-alkylidene catalyst. RSC Adv. 2018, 8, 27703-27708. [CrossRef]

22. Saunders, R.S.; Cohen, R.E.; Wong, S.J.; Schrock, R.R. Synthesis of amphiphilic star block copolymers using ring-opening metathesis polymerization. Macromolecules 1992, 25, 2055-2057. [CrossRef]

23. Liu, J.; Burts, A.O.; Li, Y.; Zhukhovitskiy, A.V.; Ottaviani, M.F.; Turro, N.J.; Johnson, J.A. “Brush-first” method for the parallel synthesis of photocleavable, nitroxide-labeled poly (ethylene glycol) star polymers. J. Am. Chem. Soc. 2012, 134, 16337-16344. [CrossRef]

24. Liao, L.; Liu, J.; Dreaden, E.C.; Morton, S.W.; Shopsowitz, K.E.; Hammond, P.T.; Johnson, J.A. A convergent synthetic platform for single-nanoparticle combination cancer therapy: Ratiometric loading and controlled release of cisplatin, doxorubicin, and camptothecin. J. Am. Chem. Soc. 2014, 136, 5896-5899. [CrossRef]

25. Burts, A.O.; Gao, A.X.; Johnson, J.A. Brush-first synthesis of core-photodegradable miktoarm star polymers via ROMP: Towards photoresponsive self-assemblies. Macromol. Rapid Commun. 2014, 35, 168-173. [CrossRef] [PubMed]

26. Barnes, J.C.; Bruno, P.M.; Nguyen, H.V.-T.; Liao, L.; Liu, J.; Hemann, M.T.; Johnson, J.A. Using an RNAi signature assay to guide the design of three-drug-conjugated nanoparticles with validated mechanisms, in vivo efficacy, and low toxicity. J. Am. Chem. Soc. 2016, 138, 12494-12501. [CrossRef] [PubMed]

27. Nguyen, H.V.-T.; Chen, Q.; Paletta, J.T.; Harvey, P.; Jiang, Y.; Zhang, H.; Boska, M.D.; Ottaviani, M.F.; Jasanoff, A.; Rajca, A.; et al. Nitroxide-based macromolecular contrast agents with unprecedented transverse relaxivity and stability for magnetic resonance imaging of tumors. ACS Cent. Sci. 2017, 3, 800-811. [CrossRef] [PubMed]

28. Shibuya, Y.; Nguyen, H.V.-T.; Johnson, J.A. Mikto-brush-arm star polymers via cross-linking of dissimilar bottlebrushes: Synthesis and solution morphologies. ACS Macro Lett. 2017, 6, 963-968. [CrossRef]

29. Nguyen, H.V.-T.; Gallagher, N.M.; Vohidov, F.; Jiang, Y.; Kawamoto, K.; Zhang, H.; Park, J.V.; Huang, Z.; Ottaviani, M.F.; Rajca, A.; et al. Scalable Synthesis of Multivalent Macromonomers for ROMP. ACS Macro Lett. 2018, 7, 472-476. [CrossRef]

30. Kalow, J.A.; Swager, T.M. Synthesis of miktoarm branched conjugated copolymers by ROMPing in and out. ACS Macro Lett. 2015, 4, 1229-1233. [CrossRef] [PubMed]

31. Buchmeiser, M.R. Ring-opening metathesis polymerization-derived materials for separation science, heterogeneous catalysis and tissue engineering. Macromol. Symp. 2010, 298, 17-24. [CrossRef]

32. Lubbad, S.; Buchmeiser, M.R. A new approach to high-capacity functionalized monoliths via post-synthesis grafting. Macromol. Rapid Commun. 2003, 24, 580-584. [CrossRef]

33. Mayr, M.; Wang, D.; Kröll, R.; Schuler, N.; Prühs, S.; Fürstner, A.; Buchmeiser, M.R. Monolithic disk-supported metathesis catalysts for use in combinatorial chemistry. Adv. Synth. Catal. 2005, 347, 484-492. [CrossRef]

34. Buchmeiser, M.R. Metathesis polymerization: A versatile tool for the synthesis of surface-functionalized supports and monolithic materials. In Handbook of Metathesis; Grubbs, R.H., Ed.; Wiley-VCH: Weinheim, Germany, 2003; Volume 3, pp. 226-254.

35. Buchmeiser, M.R. Polymer-supported well-defined metathesis catalysts. Chem. Rev. 2009, 109, $303-321$. [CrossRef]

36. Schrock, R.R. The discovery and development of high oxidation state Mo and W imido alkylidene complexes for alkene metathesis. In Handbook of Metathesis; Grubbs, R.H., Ed.; Wiley-VCH: Weinheim, Germany, 2003; Volume 1, pp. 8-32. 
37. Schrock, R.R. Recent Advances in High Oxidation State Mo and W Imido Alkylidene Chemistry. Chem. Rev. 2009, 109, 3211-3226. [CrossRef] [PubMed]

38. Murphy, J.J.; Furusho, H.; Paton, R.M.; Nomura, K. Precise synthesis of poly(macromonomer)s containing sugars by repetitive ROMP and their attachments to poly(ethylene glycol): Synthesis, TEM analysis and their properties as amphiphilic block fragments. Chem. Eur. J. 2007, 13, 8985-8997. [CrossRef] [PubMed]

39. Gestwicki, J.E.; Cairo, C.W.; Strong, L.E.; Oetjen, K.A.; Kiessling, L.L. Influencing receptor-ligand binding mechanisms with multivalent ligand architecture. J. Am. Chem. Soc. 2002, 124, 14922-14933. [CrossRef] [PubMed]

40. Schrock, R.R.; Murdzek, J.S.; Bazan, G.C.; Robbins, J.; Dimare, M.; O’Regan, M.B. Synthesis of molybdenum imido alkylidene complexes and some reactions involving acyclic olefins. J. Am. Chem. Soc. 1990, 112, 3875-3886. [CrossRef]

41. Stille, J.K.; Frey, D.A. Tetracyclic dienes. I. The Diels-Alder adduct of norbornadiene and cyclopentadiene. J. Am. Chem. Soc. 1959, 81, 4273-4275. [CrossRef]

(C) 2018 by the authors. Licensee MDPI, Basel, Switzerland. This article is an open access article distributed under the terms and conditions of the Creative Commons Attribution (CC BY) license (http://creativecommons.org/licenses/by/4.0/). 